\title{
A Controlled Pre-Post Evaluation of a Computer-based HIV/AIDS Education on Students' Sexual Behaviors, Knowledge and Attitudes
}

\author{
Angella Musiimenta ${ }^{1}$ \\ ${ }^{1}$ Mbarara University of Science and Technology, and Bishop Stuart University Kakoba
}

\begin{abstract}
Unlike traditional approaches to sexuality and HIV education which can be constrained by the sensitive nature of the subject, Information Technology (IT) can be an innovative teaching tool that can be used to educate people about HIV. This is especially relevant to interventions targeting young people; the population group fond of using IT, and the same group that is more vulnerable to HIV/AIDS. Yet, there are significantly few empirical studies that rigorously evaluated computer-assisted school-based HIVIAIDS interventions in developing countries. The modest studies conducted in this area have largely been conducted in developed countries, leaving little known about the effectiveness of such interventions in low resource settings, which moreover host the majority of HIV/AIDS infections.
\end{abstract}

This research addresses this gap by conducting a controlled pre-post intervention evaluation of the impacts of the World Starts With Me (WSWM), a computer-assisted HIV/AIDS intervention implemented in schools in Uganda. The research question was: did the WSWM intervention significantly influence students' sexual behaviors, HIVIAIDS knowledge, attitudes and self-efficacy? To address this question, questionnaires were simultaneously administering to 146 students in an intervention group (the group receiving the WSWM intervention) and 146 students in a comparison group (the group who did not receive the WSWM intervention), before (February 2009) and after the intervention (December 2009).

Findings indicate that the intervention significantly improved students' HIV/AIDS knowledge, attitudes self-efficacy, sex abstinence and fidelity, but had no significant impact on condom use. The major reason for non-use of condoms was lack of knowledge about condom use which can be attributed to teachers' failure and inabilities to demonstrate condom use in class. To address this challenge, intervention teachers should be continuously trained in skills-based and interactive sexuality education. This training will equip them with self-confidence and interactive teaching skills, including tactics for emphasizing building students' skills through role plays and interactive assignments. In addition, the HIV interventions themselves should include interactive virtual condom use demonstrations that can be accessed by students themselves. 
A Controlled Pre-Post Evaluation of a Computer-based HIV/AIDS Education on Students' Sexual Behaviors, Knowledge and Attitudes

Key words: ICT for HIVIAIDS; WSWM; sexual behaviors, knowledge and attitudes; school.

\section{Introduction}

\subsection{Computer-assisted Behavioral Change Interventions}

The literature on the effectiveness of computer-assisted behavioral change interventions reports some success in increasing knowledge (Coumba et al 2005; Campbell et al 2004), changing attitudes, and coping self-efficacy (Wikgren 2003; Stout et al 2001; Gustafson et al 2001; Richie et al 2000). However, computer-assisted behavioral change interventions are reported to have limited success in changing behavior and yielding quantifiable health benefits (Littlejohns et al 2003; Hersh et al 2001; Campbell 2004; Eysenbach et al 2004; Howells et al 2002).

Although there are significantly few empirical studies focusing on computer-assisted HIV/AIDS interventions, the modest studies conducted in this area show some positive benefits. There is evidence that computer-assisted HIV/AIDS innovations increase participants' knowledge of sexual health and HIV/AIDS (Bailey et al 2010; Young and Rice 2011; Noar et al 2009; Tian et al 2007; Ito et al 2008; Lou et al 2006; Halpern et al 2008), attitudes and self-efficacy (Gustafson et al 2001; Ashton et al 2005; Coursaris et al 2009). The efficacy of such interventions on changing sexual behavior such as condom use remains inconclusive (Bailey et al 2010; Bull et al 2009; Wantland et al 2004). However some studies report positive impacts such as reduction of risky sexual behaviors (Young and Rice 2011), condom use intentions (Ito et al 2008); significant reduction on number of partners, and increased condom use (Noar et al 2009). Despite the potential benefits, most of these studies have been conducted in developed countries, leaving little known about the effectiveness of computer-assisted HIV/AIDS interventions in developing countries. Moreover, the loss of life, and the social and economic burdens created by HIV/AIDS (e.g. carer burdens on affected families, lost output in productivity and burdens on healthcare facilities are sufficiently severe to justify the need for targeting research and intervention to the prevention of HIV/AIDS in developing countries (Muller 2005).

\subsection{The Evaluation of School-based Sexuality and HIV/AIDS Interventions}

Although there is some evidence from previous studies of increased HIV/AIDS knowledge and attitudes from school-based HIV/AIDS intervention (Cheng et al 2008; Jahanfar et al 2009), impacts on sexual behavior remain inconclusive as the same studies report no differences in students' behavioral scores. Out of 49 interventions to prevent HIV/AIDS and pregnancy in the United States, only four interventions increased the use of condoms or other contraceptives (Kirby et al 1995). Another review of 26 pregnancy prevention interventions (including 10 school-based ones) reported no effect on sex abstinence, condom use or unplanned pregnancy (DiCenso et al 2002). It can be argued that the absence of significant effects on behavioral change is a result of limited behavioral-gap due to the shortness of follow-up assessments that are normally allowed by school-based evaluation. However, results from Walker et al (2006) defeat this argument, since even the increase in condom use 
reported immediately after the intervention could not be maintained one year after the intervention. In addition, in a long follow-up, Wight et al (2002) report no statistically significant difference on students' rate of contraception uptake.

Noteworthy, however, is that some reviews indicate that school-based interventions can decrease students' HIV/AIDS risky behavior (Lonczak et al 2002). Overall, whether or not school-based HIV/AIDS interventions influence students' sexual behavior remains highly controversial. In addition, school-based HIV/AIDS studies have largely been conducted in developed countries, leaving little known about the effectiveness of such interventions in low resource settings, which moreover host the majority of HIV/AIDS infections.

Recent meta-analyses persistently caution of a lack of rigorous evaluation of school-based HIV/AIDS interventions in Africa (Magnussen et al 2004; Paul-Ebhohimhen et al 2008), while a recent literature review of 87 studies, $70 \%$ of which were school-based, affirms a lack of evaluated sexuality and HIV interventions in developing countries (UNESCO 2009). Uganda is among the Sub-Saharan African countries that has been severely infected and affected by HIV/AIDS since 1982. Although the country had recorded a decline in HIV/AIDS rates in 1990's, the rates started increasing again especially among the youth (Ministry of Health Uganda 2005; Biraro et al 2009). This increase has attracted some local and international organisations to implement HIV interventions targeting young people, of which the World Starts With Me (WSWM) the intervention evaluated in this study is one of such interventions. This investigation aimed to assess the level of significance of the impacts of the WSWM on students' sexual behaviors, knowledge of HIV/AIDS, attitudes and perceived self-efficacy.

\section{Methodology}

\subsection{The World Starts With Me (WSWM) intervention}

Developed by Butterfly Works, SchoolNet Uganda and Uganda local experts, the WSWM is a fourteen-lesson computer-assisted sexuality and HIV/AIDS intervention implemented in over 200 secondary schools in Uganda since 2003. This intervention has also been implemented in Kenya, India, Thailand, Indonesia, and Vietnam under the same sponsorship of World Population Foundation (WPF). In Uganda, it is delivered in classrooms with the help of oriented intervention teachers using the web-based version (http://www.theworldstarts.org), the CD-ROM and/or the hard copy version. By 2008, over 8,000 young people had accessed the intervention website, 2000 young people had accessed the intervention print-outs. Other IT-related features of this intervention include the online counselling and support centre (http://schoolnetuganda.sc.ug/wswmonlinesupport/) that enables the exchange of sexual health and HIV/AIDS-related information between sexual reproductive health counsellors and young people. Included also is the use of virtual peer educators, interactive safer sex quizzes, story boards, and role plays.

\subsection{The Intervention and Control Groups}

The major objective of this investigation was to assess the level of statistical significance of the impacts of the WSWM intervention on students. To achieve this objective, this investigation involved the intervention group and the comparison group (the group that never had the intervention). Investigating the intervention and comparison groups before and after 
the intervention improves the reliability with which the identified intervention impacts can be attributed to the intervention, rather than to external factors (Wyatt 2000; Remenyi et al 2002; Wyatt and Wyatt 2003).

The controlled pre-post intervention study is based on the second cycle of the intervention that ran from February 2009-December 2009. The comparison school did not implement the intervention at any time prior to or during the period of this research. Permission to investigate the intervention school was obtained from the intervention leader (the Executive and Training Director-ETD) between May and September 2008. This school was selected due to the researcher's initial contact with the intervention teachers, the anticipated high HIV vulnerability of students since it was a school in a military barracks with many war-orphaned students, and the school's close proximity to the researcher's residence. The intervention teachers used three computers connected on the internet, one Television set that used an intervention $\mathrm{CD}$, and computer print-outs to deliver the intervention. Authorisation to investigate the comparison school was obtained from the head of school in January 2009. This comparison school was selected due to the anticipated similarities with the intervention school since it was also located in a military barracks with many war-orphaned students. As shown in table 1 below, there was no statistically significant difference in the demographic characteristics of the intervention and comparison groups at pre-test.

\subsection{Participant Selection}

The researcher had no control regarding the implementation procedures of the intervention including the enrollment of students into the intervention. Thus, this investigation relied on groups that pre-existed in schools. The school's fixed implementation procedures and timetables of the intervention dictated the choice and the number of participants. The intervention school had a total of 180 students in senior one, 83 of whom were in stream A, while 77 were in stream B. In February 2009 when this study started, 152 students had registered their names to attend the intervention, all of whom were involved in the pre-test assessment of this study. The comparison group had a total of 218 students in senior one in three streams i.e. 72 students in stream A, 76 in stream B and 70 in stream C. In order to get a relatively equal number of participants in the intervention and comparison groups, stream $\mathrm{A}$ and stream B (148 participants) were involved in the present study. In both schools, participants were requested by intervention teachers to enroll for this study and were also informed that their participation had no impact on their academic assessment.

\subsection{Outcome Measures}

\subsubsection{Sexual behaviors}

There were three main measures for sexual behaviors: abstinence, number of sexual partners and condom use, which were measured using 5 statements as shown in table 2. Participants were also asked to state reasons for use or non-use of condoms at last sex.

\subsubsection{HIV/AIDS awareness and perception of vulnerability}

Seven statements were employed to measure these variables (table 4). The questions were extracted from a questionnaire that had been specifically previously developed by the Centre for AIDS Prevention Studies, California and pilot-tested on junior high school students in California (Population Council 2008). Using previously developed and tested questions 
ensures reliability of findings (Wyatt and Wyatt 2003). Some questions on AIDS-related knowledge that the present study rendered culturally inappropriate were excluded.

Each statement was assessed using a four-point Likert scale measuring the degree of agreement or disagreement with the statement, ranging from "strongly agree" to "strongly disagree" including an option for "no answer".

\subsubsection{Attitudes towards Girls' Condom Initiation and Negotiation}

This assessment used eight statements adapted from a questionnaire which was developed, validated and used in a programme for HIV prevention in Thai schools (Population Council 2008). Only statements related to attitudes towards young women's condom use were adapted (table 5). Minor adjustments were made to statements in order to emphasise girls' initiation and negotiation of condom use. This was done by introducing the word "girl" in many of the statements. For example, a statement such as: "If I carry a condom, my partner will think that I am planning to have sex", was adjusted to "If a girl carries a condom, her partner will think that she is planning to have sex." Each statement was assessed using a fourpoint Likert scale measuring the degree of agreement or disagreement with the statement, ranging from "strongly agree" to "strongly disagree" including the option for "no answer".

\subsubsection{Adherence to men's infidelity-related norms}

Participants were asked the extent to which they believe in the statement: "Whereas it is ok for boys/men to have more than one sexual partner at the same time, girls/women should only have one sexual partner at the same time". A four-point Likert scale was used to measure the degree of agreement or disagreement with the above statement, ranging from "strongly agree" to "strongly disagree", including the option for "no answer".

\subsubsection{Girls' perceptions of condom assertiveness self-efficacy}

Girls' perceptions of condom assertiveness self-efficacy were assessed by the Sexual Assertiveness Scale (SAS) (Population Council 2008), which has a proven reliability among diverse female populations. SAS was developed and validated from four studies that sampled 513 young women of at least 18 years of age. In line with aim of the present study, SAS's subscale for Pregnancy-STD prevention was adapted. No major modifications were made to the statements apart from replacing the term "latex barrier" with the term "condom". This is was after realising from pilot tests of the questionnaires that the majority of respondents had never heard about latex barriers. Five statements (table 7) were assessed using a four-point likert scale measuring the degree of agreement with each statement, ranging from "strongly agree" to "strongly disagree", including the option for "no answer."

\subsection{The Pre-Test and Post-Test Data Collection}

The pre-test and post-test studies consisted of the simultaneous administering of the same questionnaire to both the intervention and comparison groups at pre-test in February 2009, one week before the intervention group was exposed to the intervention, and at post-test in December 2009 one week after the intervention group was exposed to the intervention.

The pre-test questionnaire was aimed at exploring the initial status of students' sexual behaviors, HIV/AIDS knowledge, HIV-related self-efficacy and attitudes. These results were later used as a basis for comparison when explaining the impacts of the intervention. 
The post-test questionnaire was aimed at exploring the immediate impact of the intervention on students' sexual behaviors, HIV/AIDS knowledge, self-efficacy and attitudes. Both the pre-test and post-test questionnaires were the same in content, except that demographic questions were only included in the pre-test questionnaires.

The pre-test involved 300 participants, of whom 152 were in the intervention group and 148 in the comparison group. However, the post-test involved 292 participants, of whom 146 belonged to the intervention group, while 146 were in the comparison group. During the posttest assessment, eight participants were absent from their respective schools and were therefore excluded from the study. For both the pre-test and post-test of the intervention and comparison groups, participants were gathered in one hall where questionnaires were distributed and collected immediately after completing them. Questionnaires were administered by peers (who were class leaders) rather than the researcher as it was anticipated that participants were more likely to open up while filling in the questionnaires distributed by peers rather than the researcher. Prior to administering the questionnaires, the researcher introduced the objectives of the questionnaire to the participants. This introduction involved assuring participants of the confidentiality of the information being collected, and giving them codes that were to be used as reference points during the post-study follow-up. Peers were briefed about the contents of the questionnaire as well as about questionnaire administering. The researcher remained within the school environment while peers administered the questionnaires in order to attend to any queries that peers would not be able to answer. The total duration taken by participants to fill in the questionnaire ranged between 15-30 minutes.

\subsection{The Pre-Test and Post-Test Data Analysis}

The pre-test and post-test data collected from the groups was coded, entered and entered into SPSS version 16.0 for analysis. Responses to Likert-scaled statements were treated as ordinal/ranked variables and assigned codes; code 1 for "strongly agree" to code 4 for "strongly disagree", and 5 for "no answer". None of the respondents selected the "no answer" option, thus, this option was ignored.

Wilcoxon Signed Rank Test was employed to assess the level of significance of impacts of the intervention on sexual behaviors. Wilcoxon Signed Rank Test requires two nominal variables and one measurement variable (Pallant 2007). In this study, pre-test and post-test scores represent the first nominal variable, assessment statements represent the second nominal variable, while percentages represent measurement variable (e.g. see McDonald 2008). Response for the assessments of sexual behaviors were given numerical codes, treated as nominal variables and summarised using descriptive statistics. The statistics were then treated as continuous variables and analysed using Wilcoxon Signed Rank Test. This approach is recommended by (McDonald 2008) for "ambiguous variables" which seem not to perfectly qualify for continuous, nominal or ordinal/ranked variables, as is the case in the variables used for assessment of sexual behaviors.

Paired-sample t-tests were applied to assess the impacts of the intervention by comparing the, HIV/AIDS knowledge, attitudes and self-efficacy at the pre-test and post-test assessments of the intervention group. The paired samples t-test (also referred to as repeated measures) is a statistical measure used to assess the level of significance in mean scores of a group, or more than one group, investigated at pre-test and at post-test (Pallant 2007). Wilcoxon Signed Rank Test and paired sample t-tests calculate the probability (p) values of responses in each statement for pre and post assessments to determine the level of significance. $\mathrm{P}<=0.05$

Online Journal of Public Health Informatics * ISSN 1947-2579* http://ojphi.org * Vol.4, No. 1, 2012 
implies a statistical significance difference, while $\mathrm{P}>=0.05$ denotes an insignificant difference (Pallant 2007). Paired sample t-tests have also been effectively used by other researchers (Jahanfar et al 2009) evaluating HIV interventions that involved the pre-test and post-test assessments.

\subsection{Social-Demographic Details of Participants}

Table 1: Descriptive Statistics for the Social-demographic variables for the intervention and the comparison groups at pre-test

\begin{tabular}{|c|c|c|c|c|c|c|}
\hline Variable & \multicolumn{3}{|c|}{$\begin{array}{l}\text { Intervention group } \\
(\operatorname{Max} \mathrm{n}=146)\end{array}$} & \multicolumn{3}{|c|}{$\begin{array}{l}\text { Comparison group } \\
(\operatorname{Max} n=146)\end{array}$} \\
\hline Sex & $\begin{array}{c}\text { Male } \\
=61(42 \%)\end{array}$ & $\begin{aligned} & \text { Female } \\
= & 85(58 \%)\end{aligned}$ & $\begin{array}{c}\text { Total } \\
=146(100 \%)\end{array}$ & $\begin{array}{c}\text { Male } \\
=46(32 \%)\end{array}$ & $\begin{array}{c}\text { Female } \\
=100(68 \%)\end{array}$ & $\begin{array}{c}\text { Total } \\
=146(100 \%)\end{array}$ \\
\hline $\begin{array}{c}\text { Age (years) } \\
11-13 \\
14-16\end{array}$ & $\begin{array}{l}24(16 \%) \\
37(25 \%)\end{array}$ & $\begin{array}{l}17(12 \%) \\
68(47 \%)\end{array}$ & $\begin{array}{c}41(28 \%) \\
105(72 \%) \\
n=146(100 \%)\end{array}$ & $\begin{array}{l}14(10 \%) \\
32(22 \%)\end{array}$ & $\begin{array}{l}23(15 \%) \\
77(53 \%)\end{array}$ & $\begin{array}{c}37(25 \%) \\
109(75 \%) \\
n=146(100 \%)\end{array}$ \\
\hline $\begin{array}{l}\text { Religion } \\
\text { Christian } \\
\text { Muslim }\end{array}$ & $\begin{array}{l}47(32 \%) \\
14(10 \%)\end{array}$ & $\begin{array}{c}80(55 \%) \\
5(3 \%)\end{array}$ & $\begin{array}{c}127(87 \%) \\
19(13 \%) \\
n=146(100 \%)\end{array}$ & $\begin{array}{c}44(30 \%) \\
2(1 \%)\end{array}$ & $\begin{array}{c}89(61 \%) \\
11(8 \%)\end{array}$ & $\begin{array}{c}133(91 \%) \\
13(9 \%) \\
n=146(100 \%)\end{array}$ \\
\hline $\begin{array}{l}\text { Parental status } \\
\text { One or both parent } \\
\text { dead }\end{array}$ & $\begin{array}{l}49(34 \%) \\
12(8 \%)\end{array}$ & $\begin{array}{l}57(39 \%) \\
28(19 \%)\end{array}$ & $\begin{array}{c}106(73 \%) \\
40(27 \%) \\
n=146(100 \%)\end{array}$ & $\begin{array}{l}34(23 \%) \\
12(8 \%)\end{array}$ & $\begin{array}{l}63(43 \%) \\
37(25 \%)\end{array}$ & $\begin{array}{c}97(66 \%) \\
49(34 \%) \\
n=146(100 \%)\end{array}$ \\
\hline $\begin{array}{c}\text { Parent } \\
\text { occupation }^{1} \\
\text { Non-professionals } \\
\text { Professionals }\end{array}$ & $\begin{array}{c}50(34 \%) \\
11(8 \%)\end{array}$ & $\begin{array}{l}67(46 \%) \\
18(12 \%)\end{array}$ & $\begin{array}{c}117(80 \%) \\
29(20 \%) \\
\mathrm{n}=146(100 \%)\end{array}$ & $\begin{array}{c}43(30 \%) \\
3(2 \%)\end{array}$ & $\begin{array}{l}85(58 \%) \\
15(10 \%)\end{array}$ & $\begin{array}{c}128(88 \%) \\
18(12 \%) \\
n=146(100 \%)\end{array}$ \\
\hline $\begin{array}{l}\text { Max n = Maximum } \\
{ }^{1} \text { Professional occu } \\
\text { soldiers, shop keep }\end{array}$ & $\begin{array}{l}\text { nber of } 1 \\
\text { on incluc } \\
\text { and farm }\end{array}$ & $\begin{array}{l}\text { pants. } \\
\text { gineers, }\end{array}$ & rs, and teac & on-pro & al occup & include \\
\hline
\end{tabular}

The majority of students were within the age range of 14-16 years, were Christians, orphans, and had parents with non-professional jobs. Family background e.g. a lack of parents or poverty may explain the wide age range in senior one. 
A Controlled Pre-Post Evaluation of a Computer-based HIV/AIDS Education on Students' Sexual Behaviors, Knowledge and Attitudes

\section{Results}

\subsection{Impact on Sexual Behaviors}

Table 2: Wilcoxon Signed Rank Test demonstrating the differences in sexual behaviors between pre-test and post-test for the intervention and the comparison groups

\begin{tabular}{|c|c|c|c|c|c|c|c|c|c|}
\hline \multirow[t]{2}{*}{ Sexual behaviors } & \multirow[t]{2}{*}{$\begin{array}{l}\text { Assessment } \\
\text { statements }\end{array}$} & \multicolumn{3}{|c|}{$\begin{array}{l}\text { Intervention group } \\
(\mathrm{n}=\mathbf{1 4 5})\end{array}$} & \multicolumn{3}{|c|}{$\begin{array}{l}\text { Comparison group } \\
(n=145)\end{array}$} & \multicolumn{2}{|c|}{$\begin{array}{l}\text { Paired } \\
\text { intervention \& } \\
\text { comparison } \\
(\mathrm{n}=145)\end{array}$} \\
\hline & & $\operatorname{Pre}(\%)$ & $\operatorname{post}(\%)$ & $\mathrm{P}$ & $\operatorname{Pre}(\%)$ & $\operatorname{post}(\%)$ & $\mathrm{P}$ & $\operatorname{Pre}(\mathrm{P})$ & $\operatorname{post}(\mathrm{P})$ \\
\hline \multirow{3}{*}{$\begin{array}{l}\text { Number of } \\
\text { partners/abstinence }\end{array}$} & $\begin{array}{l}\text { Not had sex } \\
\text { in the last } \\
\text { three months }\end{array}$ & 61 & 73 & 0.00 & 59 & 58 & 0.16 & 016 & 0.00 \\
\hline & $\begin{array}{l}\text { Had sex with } \\
1 \text { partner in } \\
\text { the last } 3 \\
\text { months. }\end{array}$ & 22 & 12 & 0.00 & 23 & 21 & 0.16 & 0.32 & 0.00 \\
\hline & $\begin{array}{l}\text { Had sex with } \\
2 \text { or more } \\
\text { partners in the } \\
\text { last } 3 \text { month }\end{array}$ & 17 & 14 & 0.05 & 15 & 17 & 0.08 & 0.83 & 0.05 \\
\hline \multirow[t]{2}{*}{ Condom use } & $\begin{array}{l}\text { Ever used } \\
\text { condom }\end{array}$ & 45 & 46 & 0.32 & 43 & 44 & 0.60 & 0.08 & 0.57 \\
\hline & $\begin{array}{l}\text { Used condom } \\
\text { at last sex }\end{array}$ & 23 & 25 & 0.64 & 21 & 23 & 0.26 & 0.08 & 0.64 \\
\hline
\end{tabular}

Compared to comparison group, the intervention had a statistically significant influence on students' sex abstinence; (from $61 \%$ at pre-intervention to $73 \%$ at post-intervention; $\mathrm{p}=0.00$ ) reporting not to have had sex in the last three months. Having sex with one partner in the last three months significantly reduced from $22 \%$ to $12 \% ; \mathrm{p}=0.00$, while having sex with two or more partners significantly reduced from $17 \%$ to $14 ; \mathrm{p}=0.00$. However, the intervention had no significant impact on students' condom use. Three factors strongly contributed to students' non-use of condoms at last sex: lack of knowledge of using condoms $(25 \%)$; feelings of embarrassment associated with buying and suggesting condom use (21) \%; and perceptions that one can still get HIV/AIDS even if condoms are used (3\%). 


\subsection{Impact on HIV/AIDS Awareness and Perception of Vulnerability}

Table 4: Paired sample t-tests demonstrating the HIV/AIDS knowledge scores for the intervention and comparison groups at pre-test and post-test

\begin{tabular}{|c|c|c|c|c|c|c|c|c|c|c|}
\hline \multirow[t]{2}{*}{$\begin{array}{l}\text { Knowledge assessment } \\
\text { statements }\end{array}$} & \multicolumn{4}{|c|}{$\begin{array}{l}\text { Intervention group } \\
(n=146)\end{array}$} & \multicolumn{4}{|c|}{$\begin{array}{l}\text { Comparison group } \\
(n=146)\end{array}$} & \multicolumn{2}{|c|}{$\begin{array}{l}\text { Paired } \\
\text { intervention } \& \\
\text { comparison } \\
(n=146)\end{array}$} \\
\hline & M1 & M2 & $\mathrm{SD}$ & $\mathrm{p}$ & M1 & M2 & SD & $\mathrm{p}$ & $\mathrm{p} 1$ & $\mathrm{p} 2$ \\
\hline $\begin{array}{l}\text { Showering, or washing one's } \\
\text { private parts after sex keeps a } \\
\text { person from getting HIV/AIDS }\end{array}$ & 3.33 & 3.51 & 0.38 & 0.00 & 3.25 & 3.30 & 0.47 & 0.22 & 0.07 & 0.00 \\
\hline $\begin{array}{l}\text { Eating healthy foods can keep a } \\
\text { person from getting HIV/AIDS }\end{array}$ & 3.42 & 3.58 & 0.36 & 0.00 & 3.37 & 3.38 & 0.83 & 0.32 & 0.25 & 0.00 \\
\hline $\begin{array}{l}\text { Taking the Birth Control Pill } \\
\text { keeps a woman from getting } \\
\text { HIV/AIDS }\end{array}$ & 3.24 & 3.61 & 0.56 & 0.00 & 3.18 & 3.23 & 0.32 & 0.07 & 0.06 & 0.00 \\
\hline $\begin{array}{l}\text { A person with HIV/AIDS can } \\
\text { look and feel healthy }\end{array}$ & 2.62 & 2.34 & 1.41 & 0.02 & 2.55 & 2.56 & 0.33 & 0.62 & 0.06 & 0.05 \\
\hline $\begin{array}{l}\text { There is a vaccine that can cure } \\
\text { people from HIV/AIDS }\end{array}$ & 3.17 & 3.50 & 0.51 & 0.00 & 3.16 & 3.21 & 0.57 & 0.39 & 0.32 & 0.00 \\
\hline $\begin{array}{l}\text { A person can get HIV/AIDS even } \\
\text { if she or he has sex with another } \\
\text { person only one time }\end{array}$ & 2.22 & 1.69 & 0.88 & 0.00 & 2.22 & 2.19 & 0.42 & 0.44 & 0.32 & 0.00 \\
\hline $\begin{array}{l}\text { People are likely to get } \\
\text { HIV/AIDS by deep kissing, } \\
\text { putting their tongue in their } \\
\text { partner's mouth, if their partner } \\
\text { has HIV/AIDS }\end{array}$ & 2.60 & 2.24 & 0.76 & 0.00 & 2.64 & 2.56 & 0.57 & 0.66 & 0.20 & 0.00 \\
\hline $\begin{array}{l}\text { M1= Mean at pre-test; } M 2=\mathrm{Me} \\
\text { p1= } \\
\text { Between-group p-value at pre-tes }\end{array}$ & $\mathrm{p}$ & es & . & dar & ev & n; & Wit & gr & $\mathrm{p}$-va & \\
\hline
\end{tabular}

Unlike the comparison group, the intervention group experienced statistically significant mean increases in the likelihood of participants to disagree with misconceptions of associating HIV/AIDS cure with washing ones private parts $(\mathrm{M} 1=3.33$ to $\mathrm{M} 2=3.51 ; \mathrm{SD}=0.38$; $\mathrm{p}=0.00$ ), eating healthy foods $(\mathrm{M} 1=3.42$ to $\mathrm{M} 2=3.58 ; \mathrm{SD}=0.36 ; \mathrm{p}=0.00)$, taking birth control pills $(\mathrm{M} 1=3.24$ to $\mathrm{M} 2=3.61 ; \mathrm{SD}=0.56 ; \mathrm{p}=0.00)$, and existence of vaccination for HIV/AIDS cure $(\mathrm{M} 1=3.17$ to $\mathrm{M} 2=3.50 ; \mathrm{SD}=; \mathrm{p}=0.00)$. The group was also significantly likely to disagree that a person can get AIDS from having sex only once $(\mathrm{M} 1=2.22$ to $\mathrm{M} 2=1.69$; $\mathrm{SD}=0.88 ; \mathrm{p}=0.00)$, can get AIDS from deep kissing ( $\mathrm{M} 1=2.60$ to $\mathrm{M} 2=2.24 ; \mathrm{SD}=0.76$; $\mathrm{p}=0.00)$, and that a person with HIV/AIDS can feel and look healthy (M1=2.62 to $\mathrm{M} 2=2.34$; $\mathrm{SD}=1.41 ; \mathrm{p}=0.02)$. 


\subsection{Attitudes towards Girls' Condom Initiation and Negotiation}

Table 5: paired sample t-tests demonstrating the attitudes towards gender equity in condom use initiation and negotiation scores for the intervention and comparison groups at pre-test and post-test

\begin{tabular}{|c|c|c|c|c|c|c|c|c|c|c|}
\hline \multirow[t]{2}{*}{$\begin{array}{l}\text { Statement for assessing } \\
\text { gender equity in condom } \\
\text { negotiation }\end{array}$} & \multicolumn{4}{|c|}{$\begin{array}{c}\text { Intervention } \\
\text { group }(n=146)\end{array}$} & \multicolumn{4}{|c|}{$\begin{array}{l}\text { Comparison group } \\
(n=146)\end{array}$} & \multicolumn{2}{|c|}{\begin{tabular}{|l|} 
Paired \\
intervention \& \\
comparison \\
$(n=146)$ \\
\end{tabular}} \\
\hline & M1 & M2 & SD & $\mathrm{p}$ & M1 & M2 & SD & $\mathrm{p}$ & P1 & $\mathrm{P} 2$ \\
\hline $\begin{array}{l}\text { If a girl carries a condom, her } \\
\text { partner will think that she is } \\
\text { planning to have sex. }\end{array}$ & 2.13 & 2.26 & 0.67 & 0.02 & 2.13 & 2.12 & 0.19 & 0.66 & 0.32 & 0.02 \\
\hline $\begin{array}{l}\text { A girl loses a man's respect if } \\
\text { she asks him to use a condom }\end{array}$ & 2.74 & 2.83 & 0.44 & 0.02 & 2.72 & 2.74 & 0.14 & 0.08 & 0.08 & 0.02 \\
\hline $\begin{array}{l}\text { It is embarrassing for a girl to } \\
\text { buy or ask for condoms }\end{array}$ & 2.14 & 2.09 & 0.33 & 0.05 & 2.16 & 2.14 & 0.50 & 0.61 & 0.25 & 0.05 \\
\hline $\begin{array}{l}\text { Using a condom is a sign of } \\
\text { girls not trusting their partner }\end{array}$ & 2.33 & 2.21 & 0.53 & 0.00 & 2.35 & 2.36 & \begin{tabular}{|l}
0.17 \\
\end{tabular} & 0.32 & 0.32 & 0.03 \\
\hline $\begin{array}{l}\text { Condom use initiation should } \\
\text { only be done by boys }\end{array}$ & 3.13 & 3.18 & 0.30 & 0.05 & 3.12 & 3.11 & 0.08 & 0.32 & 0.32 & 0.02 \\
\hline $\begin{array}{l}\text { If a girl carries a condom it } \\
\text { means they are experienced in } \\
\text { sexual matters }\end{array}$ & 2.37 & 2.44 & .0 .42 & 0.05 & 2.35 & 2.36 & 0.08 & 0.32 & 0.18 & 0.02 \\
\hline $\begin{array}{l}\text { Girls who carry condoms and } \\
\text { insist on using them are } \\
\text { prostitutes and such girls are } \\
\text { not respected }\end{array}$ & 2.39 & 2.47 & 0.42 & 0.02 & 2.40 & 2.42 & 0.17 & 0.32 & 0.32 & 0.05 \\
\hline $\begin{array}{l}\text { It is okay for a girl to suggest } \\
\text { condom use }\end{array}$ & 1.72 & 1.62 & \begin{tabular}{|l|}
0.43 \\
\end{tabular} & 0.00 & 1.74 & 1.75 & 0.08 & 0.32 & 0.18 & 0.00 \\
\hline
\end{tabular}

Unlike the comparison group, the intervention group experienced a significant mean decrease in the like hood of students to associate girl's condom carrying and negotiation with planning to have sex $(M 1=2.13, M=2.26 ; S D=0.67 ; p=0.02)$, loss of respect $(M 1=2.74, M 2=2.83$; $\mathrm{SD}=0.44 ; \mathrm{p}=0.02)$, embarrassment $(\mathrm{M} 1=2.14, \mathrm{M} 2=2.09 ; \mathrm{SD}=0.33 ; \mathrm{p}=0.05)$, lack of trust $(\mathrm{M} 1=2.33, \mathrm{SD}=0.53 ; \mathrm{M} 2=2.21 ; \mathrm{p}=0.00)$, sexual experience $(\mathrm{M} 1=2.37, \mathrm{M} 2=2.44 ; \mathrm{SD}=0.42$; $\mathrm{p}=0.05$ ), and prostitution $(\mathrm{M} 1=2.39, \mathrm{M} 2=2.47 ; \mathrm{SD}=0.42 ; \mathrm{p}=0.02)$. Unlike the comparison group, the intervention group significantly disagree that condom use initiation should only be done by boys $(\mathrm{M} 1=3.13, \mathrm{M} 2=3.18 ; \mathrm{SD}=0.30 ; \mathrm{p}=0.05)$, and significantly agree that girls can suggest condom use $(\mathrm{M} 1=1.72, \mathrm{M} 2=1.62 ; \mathrm{SD}=0.43 ; \mathrm{p}=0.00)$. 


\subsection{Attitudes towards Men's Infidelity-related Norms}

Table 6: Paired sample t-tests demonstrating the attitudes towards norms that condone multiple sexual partners for men for the intervention and comparison groups at pre-test and post-test

\begin{tabular}{|c|c|c|c|c|c|c|c|c|c|c|}
\hline \multirow[t]{2}{*}{$\begin{array}{l}\text { Statement for assessing } \\
\text { attitude towards norms } \\
\text { condoning men's multiple } \\
\text { sexual partners }\end{array}$} & \multicolumn{5}{|c|}{$\begin{array}{c}\text { Intervention } \\
\text { group }(n=145)\end{array}$} & \multicolumn{3}{|c|}{$\begin{array}{l}\text { Comparison } \\
\text { group }(n=145)\end{array}$} & \multicolumn{2}{|c|}{$\begin{array}{l}\text { Paired } \\
\text { intervention \& } \\
\text { comparison } \\
(\mathbf{n}=\mathbf{1 4 5})\end{array}$} \\
\hline & M1 & M2 & SD & $\mathrm{p}$ & M1 & M2 & SD & $\mathrm{p}$ & P1 & P2 \\
\hline $\begin{array}{l}\text { Whereas it is ok for boys/men } \\
\text { to have more than one sexual } \\
\text { partner at the same time, } \\
\text { girls/women should only have } \\
\text { one sexual partner at one time }\end{array}$ & 2.56 & 2.75 & 0.81 & 0.00 & 2.55 & 2.57 & 0.60 & 0.68 & 0.78 & 0.03 \\
\hline
\end{tabular}

Unlike the comparison group $(\mathrm{M} 1=2.45, \mathrm{M} 2=2.57 ; \mathrm{SD}=0.60 ; \mathrm{p}=0.68)$, the intervention group experienced statistically significant mean increases $(\mathrm{M} 1=2.56, \mathrm{M} 2=2.75 ; \mathrm{SD}=0.81 ; \mathrm{p}=0.00)$ in the likelihood of participants to disagree that men should have multiple sexual partners while at the same time women should have only one partner.

\subsection{Impact on Girls' Sexual and Condom Assertiveness Self-efficacy}

Table 7: paired sample t-tests demonstrating girls' perceived condom assertiveness selfefficacy scores for the intervention and comparison at both pre-test and post-test

\begin{tabular}{|c|c|c|c|c|c|c|c|c|c|c|}
\hline \multirow{2}{*}{$\begin{array}{l}\text { Statements used to assess } \\
\text { girls' perceived condom } \\
\text { assertiveness self-efficacy }\end{array}$} & \multicolumn{4}{|c|}{$\begin{array}{l}\text { Intervention group } \\
(\mathrm{n}=\mathbf{8 4})\end{array}$} & \multicolumn{4}{|c|}{$\begin{array}{l}\text { Comparison group } \\
(n=84)\end{array}$} & \multicolumn{2}{|c|}{$\begin{array}{l}\text { Paired } \\
\text { intervention \& } \\
\text { comparison }(n=84)\end{array}$} \\
\hline & M1 & M2 & SD & $\mathbf{p}$ & M1 & M2 & SD & p & P1 & P2 \\
\hline $\begin{array}{l}\text { I could have sex without a } \\
\text { condom if my partner doesn't } \\
\text { like them, even if I want to use } \\
\text { one. }\end{array}$ & 3.05 & 3.39 & 1.05 & 0.00 & 3.03 & 3.01 & 0.22 & 0.32 & 0.32 & 0.00 \\
\hline $\begin{array}{l}\text { I could make sure my partner } \\
\text { and I use a condom when we } \\
\text { have sex. }\end{array}$ & 2.09 & 1.48 & 1.26 & 0.00 & 2.11 & 2.09 & 0.15 & 0.16 & 0.16 & 0.00 \\
\hline $\begin{array}{l}\text { I could have sex without using a } \\
\text { condom if my partner wants }\end{array}$ & 3.00 & 3.43 & 1.11 & 0.00 & 2.98 & 2.97 & 0.11 & 0.32 & 0.32 & 0.00 \\
\hline $\begin{array}{l}\text { I could insist on using a condom } \\
\text { even if my partner doesn't want } \\
\text { them }\end{array}$ & 2.76 & 2.45 & 0.73 & 0.00 & 2.77 & 2.75 & 0.15 & 0.16 & 0.32 & 0.00 \\
\hline $\begin{array}{l}\text { I could refuse to have sex if my } \\
\text { partner refuses to use a condom }\end{array}$ & 2.16 & 1.55 & 0.96 & 0.00 & 2.18 & 2.20 & 0.15 & 0.16 & 0.32 & 0.00 \\
\hline
\end{tabular}


Before the intervention, there were no statistically significant differences between the intervention and comparison groups regarding their perceived condom assertiveness selfefficacy. However, after the intervention, there were statistically significant differences between the two groups. This implies that the intervention had a significant effect on girls' perceived condom assertiveness self-efficacy. For example, unlike the comparison group, participants in the intervention group significantly agreed that they would make sure that they use condoms $(\mathrm{M} 1=2.09, \mathrm{M} 2=1.48 ; \mathrm{SD}=1.26 ; \mathrm{p}=0.00)$, insist on using condoms $(\mathrm{M} 1=2.76$, $\mathrm{M} 2=2.45 ; \mathrm{SD}=0.73 ; \mathrm{p}=0.05)$, and refuse to have unprotected sex $(\mathrm{M} 1=2.16, \mathrm{M} 2=1.55$; $\mathrm{SD}=0.96 ; \mathrm{p}=0.03)$.

\section{Discussion}

\subsection{Impact on sexual behaviors}

Results indicate that the intervention had significant impact on students' sex abstinence and partner faithfulness. This is similar to the contentions of previous studies investigating computer-assisted HIV interventions as they reported reduction in the number of sexual partners (Noar et al 2009), reduction in risky sexual behaviors (Young and Rice 2011). Despite the significant influence on sex abstinence and partner faithfulness, the impact on condom use was not significant. An insignificant impact of computer-assisted interventions on condom use is consistent with those of previous researchers (Bailey et al 2010; Bull et al 2009; Wantland et al 2004). Although the present study reports results of a short follow-up, a longer follow-up of 18 years olds still showed no significant impacts on unprotected sex (Stephenson et al 2004). Walker et al (2006) report students inability to maintain the behavioral impacts (condom use in particular) reported during short follow-up. Three reasons (i.e. lack of knowledge of using condoms, feelings of embarrassment associated with buying and suggesting condom use, and perceptions that one can still get HIV/AIDS even if condoms are used) largely contributed to non-use of condoms. Other mediators that constrained condom use include: perceptions that condoms cause cancer and contain germs, lack of money to buy condoms, desire to prove manhood by making girls pregnant, perception of partner trust, condoms' interference in sexual pleasure, perceptions that students don't fit in condoms resulting in condoms slipping off and remaining in a girl's body, and religious constraints. Other studies also report constraints in condom use e.g. challenges in initiation and negotiation (Sionean et al 2002), religious constraints (Mosley 2003), and partner trust (Kelly \& Parker 2000). The condom use constraint of lack of skills may have been attributed by intervention teachers' failure to practically demonstrate condom use in class as it was reported in the results of implementation evaluation. The intervention teachers' reservations on teaching about condom use ultimately influenced their level of condom emphasis and details revealed to students. Teachers' failure and inabilities to demonstrate condom use is also reported in a recent systematic review (Shepherd et al 2010).

\subsection{HIV/AIDS Knowledge}

Consistent with those other researchers (Bailey et al 2010; Young and Rice 2011; Noar et al 2010; Tain et al 2007; Ito et al 2008; Lou et al 2006; Halpern et al 2008), the present study indicates that the computer-assisted HIV/AIDS intervention significantly influenced students' knowledge of HIV/AIDS transmission and prevention. Compared to the comparison group, students in the intervention group were significantly more likely to disagree that HIV/AIDS can be prevented by: washing private parts after sex, eating healthy foods, taking birth control 
pills, and to disagree that there is a vaccination that cures HIV/AIDS. Also, compared to the comparison group, the intervention group were significantly more likely to agree that a person can get AIDS from having sex only once and deep kissing and to agree that a person with HIV/AIDS can feel and look healthy.

Although increase in knowledge does not always guarantee changes in behavior, reliable information especially about the involved risks can be vital in motivating health behavioral change (Prochaska and DiClemente 1983).

\subsection{Attitudes towards Girls' Condom Initiation and Negotiation.}

Cultural expectations of women's passiveness and ignorance in sexuality constrain their sexual negotiating power, including negotiating for safer practices (Pearson 2006). Computer-assisted HIV interventions can significantly influence people's attitudes towards HIV prevention (Coursaris et al 2009). The present study reports statistically significant improvement in students' perceptions of girls' condom negotiation, and in attitudes towards men's infidelity practices. The positive attitudes towards females' condom negotiation present an important step forward in tackling the gender-related vulnerability of HIV/AIDS and pregnancy.

\subsection{Attitudes towards and men's infidelity-related norms}

Compared to the comparison group, the intervention group experienced significant reduction in participants' adherence to the socially defined gender-biased ideologies that condone men's practice of having concurrent multiple sexual partners while constraining women's sexuality to single partners. Studies evaluating HIV school-based interventions rarely incorporate gender-related constructs in their assessments. Noteworthy, thought not schoolbased, studies such as Coursaris et al (2009) report significant influence in attitudes resulting from computer-assisted HIV interventions.

\subsection{Girls' sexual and condom assertiveness self-efficacy}

Results indicate a significant increase in girls' sexual and condom assertiveness self-efficacy. Given the persistently reported students' difficulties in practical translation of HIV knowledge to HIV prevention practices (Bazargan et al 2000), the reported improvements in HIV/AIDS knowledge and attitudes may not make significant impact on behaviors without appropriate self-efficacy to adopt HIV preventive measures. Self-efficacy plays an important role in closing the awareness-behavior gap by equipping individuals with positive capability beliefs and abilities to adopt healthy behaviors (Rimal 2000). Previous studies also report improved young women's refusal self-efficacy (Karnell et al 2006) and condom negotiation self-efficacy (Roberto et al 2007) after exposure to the sexuality intervention. While computer-assisted studies (e.g. Gustafson et al 2001; Ashton et al 2005; Coursaris et al 2009) affirm positive influence on participant's self-efficacy. Girl's condom negotiation and sexual assertiveness self-efficacy has a direct relationship with condom use (Sionean et al 2002).

The reported distinctive condom negotiation self-efficacy and sexual assertiveness can be instrumental in combating HIV/AIDS and its uneven burdensome consequences among young women. 


\section{Limitation of the Study}

If the experimental conditions permitted, rather than using pre-existing groups in two schools, randomly allocating participants to the intervention and control groups within the same school would have improved the reliability of the results. However, given the free interaction of students in the school environment, drawing groups within the same school would have been reliable to a challenge of ensuring that participants in the control group are completely uninfluenced by the intervention. Stephenson et al (2008) also warns about this potential methodological bias resulting from the spreading of the school-based sexuality interventions to control groups. In addition, this approach was not feasible due to the researcher's limited control on the implementation procedures of the intervention. Nearly all the students in senior one of the intervention group had registered to attend the intervention. This implies that there were not enough participants to be allocated to the comparison group. The only option was to draw the comparison group from another school, separate from the intervention school. Thus, rather than composing and randomly allocating groups, this study relied on groups that pre-existed in separate schools. The fixed schools' implementation procedures and timetables of the intervention dictated the choice and the number of participants. Nevertheless, the pre-test analysis indicated no significant differences between the intervention and the comparison groups.

\section{Conclusion}

This paper conducted a quantitative pre-post intervention study aimed at investigating the impacts of the computer-assisted sexuality and HIV/AIDS intervention implemented in schools in Uganda. To achieve this aim, questionnaire was administered to both the intervention group $(n=146)$ and the comparison group $(n=146)$ at pre-test (February 2009) and at post-test (December 2009).

The results indicate that the intervention significantly improved students' sex abstinence and reduction in number of sexual partners, improved knowledge and perception of vulnerability to HIV/AIDS, improved their attitudes towards gender equity in HIV/AIDS and pregnancy prevention, reduced adherence to men's infidelity-related norms and improved girls' perception of condom assertiveness self-efficacy. However, Condom use appeared to be unaffected by the intervention. Three reasons significantly contributed to non-use of condoms: lack of skills in using condoms which was mainly attributed to lack of practical condom use demonstrations in classes, feelings of embarrassment associated with buying and suggesting condom use and perceptions that one can still get HIV/AIDS even if condoms are used. Teachers training in skills-based and interactive sexuality education, inclusion of interactive virtual condom use demonstrations in the web-based version of the intervention, and community sensitisations about the role of condoms in HIV prevention can help address these condom use constraints. 


\title{
Corresponding Author
}

\author{
Angella Musiimenta \\ Senior Lecturer \\ Mbarara University of Science and Technology \\ Bishop Stuart University \\ Email: angellamusiimenta@yahoo.com
}

\section{References}

1. Ashton E, Vosvick M, Chesney M, Gore-Felton C, Koopman C, et al. 2005. Social Support and Maladaptive Coping as Predictors of the Change in Physical Health Symptoms among Persons Living with HIV/AIDS. Am J Public Health. •••, 1027-30.

2. Bailey JV, Murray E, Rait G, Mercer CH, Morris RW, et al. 2010. Interactive computerbased interventions for sexual health promotion. Cochrane Database Syst Rev. 9.

3. Bazargan M, Kelly EM, Stein JA, Hussain BA, Bazargan HS. 2000. Correlates of HIV Risk-taking Behaviors among African-American College Students. The effect of HIV Knowledge, Motivation and Behavioral Skills. J Natl Med Assoc. 92(8), 391-404.

4. Biraro S, Shafer LA, Kleinschmid I, Wolff B, Karabalinde A, et al. 2009. Is Sexual Risk Taking Behavior Changing in Rural South-West Uganda? Behavior Trends in a Rural Population Cohort 1993-2006. Sex Transm Infect. 85, i3-11. http://dx.doi.org/10.1136/ sti.2008.033928

5. Bull SS, Pratte K, Whitesell N, Rietmeijer C, McFarlane M. 2009. Effects of an Internetbased Intervention for HIV Prevention: The Youth Trials. AIDS Behav. 13, 474-87. http:// dx.doi.org/10.1007/s10461-008-9487-9

6. Campbell CA. 1995. Male Gender Roles and Sexuality: Implications for Women's AIDS Risk and Prevention. Soc Sci Med. 41(2), 197-210. http://

dx.doi.org/10.1016/0277-9536(94)00322-K

7. Coumba, M.G. (2005). Exploring the Gender Impacts of World Links in Some Selected African Countries: A Qualitative Approach. [online]. Available from: http:world-links.org/ English/assets/gender study v2.pdf [accessed on 12 August 2008].

8. Cheng Y, Lou CH, Mueller MA, Zhao SL, Yang JH, et al. 2008. Effectiveness of a Schoolbased AIDS Education Program Among Rural Students in High Epidemic Area of China. J Adolesc Health. 42, 184-91. http://dx.doi.org/10.1016/j.jadohealth.2007.07.016

9. Coursaris CK, Liu M. 2009. Analysis of Social Support Exchanges in Online HIV/AIDS Self-help Groups. Comput Human Behav. 25, 911-18. http://dx.doi.org/10.1016/ j.chb.2009.03.006

10. DiCenso A, Guyatt G, Willan A, Griffith L. 2002. Interventions to Reduce Unintended Pregnancies Among Adolescents: Systematic Review of Randomised Controlled Trial. BMJ. 324, 1-9. http://dx.doi.org/10.1136/bmj.324.7351.1426

11. Eysenbach G, Powell J, Englesakis M, Rizo C, Stern A. 2004. Health Related Virtual Communities and Electronic Support Groups: Systematic Review of the Effects of Online Peer to Peer Interactions. BMJ. 328(7449), 1166. http://dx.doi.org/10.1136/

bmj.328.7449.1166 
12. Gustafson DH, Hawkins R, Boberg E, Pingree S, Serlin RE, et al. 2001. Impact of a Patient Centred Computer-based Health Information Support. Am J Prev Med. 16(1). 13. Halpern CT, Mitchell EMH, Farhat T, Bardsley P. 2008. Effectiveness of Web-based Education on Kenyan and Brazilian Adolescents' Knowledge about HIV/AIDS, Abortion Law, and Emergency Contraception: Findings from TeenWeb. Soc Sci Med. 67, 628-37. http://dx.doi.org/10.1016/j.socscimed.2008.05.001

14. Hersh WR, Helfand M, Wallace J, Kraemer D, Patterson P, et al. 2001. Clinical Outcomes Resulting from Telemedicine Interventions: A Systematic Review. BMC Med Inform Decis Mak. 1(1), 5. http://dx.doi.org/10.1186/1472-6947-1-5

15. Howells L. 2002. A Randomised Control Trial of the Effect of Negotiated Telephone Support on Glycaemic Control in Young People with Type 1 Diabetes. Diabet Med. 19(8), 643-48. http://dx.doi.org/10.1046/j.1464-5491.2002.00791.x

16. Jahanfar S, Lye MS, Rampal L. 2009. A Randomised Controlled Trail of Peer Adult-led Intervention on Improvement of Knowledge, Attitudes and Behavior of University Students regarding HIV/AIDS in Malaysia. Singapore Med J. 50(2), 173-80.

17. Jemmott J, Jemmott L, Fong G. 2010. Efficacy of a theory-based abstinence-only intervention over 24 months: a randomized controlled trial with young adolescents. Arch Pediatr Adolesc Med. 164(2), 152-59. http://dx.doi.org/10.1001/archpediatrics.2009.267 18. Littlejohns P, Wyatt JC, Garvican L. 2003. Evaluating Computerised Health Information Systems: Hard Lessons still to be Learnt. BMJ. 326, 860-63. http://dx.doi.org/10.1136/ bmj.326.7394.860

19. Ito KE, Kalyanaraman S, Ford CA, Brown JD, Miller WC. 2008. "Let's Talk About Sex": pilot study of an interactive CD-ROM to prevent HIV/STIS in female adolescents. AIDS Educ Prev. 20(1), 78-89. http://dx.doi.org/10.1521/aeap.2008.20.1.78

20. Karnell AP, Cupp PK, Zimmerman RS, Feist-Price S, Bennie T. 2006. Efficacy of an American Alcohol and HIV Prevention Curriculum Adapted for Use in South Africa: Results of a Pilot Study in Five Township Schools. AIDS Educ Prev. 18, 295-310. http:// dx.doi.org/10.1521/aeap.2006.18.4.295

21. Kirby D. (1995). A Review of Educational Programs designed to Reduce Sexual RiskTaking Behaviors among School-aged Youth In the United States. Springfield, Virginia: National Technical Information Service.

22. Lonczak H, Abbott R, Hawkins D, Kosterman R, Catalano R. 2002. Effects of the Seattle Social Development Project on Sexual Behavior, Pregnancy, Birth and Sexually Transmitted Disease Outcomes by Age 21 Years. Arch Pediatr Adolesc Med. 156, 438-47. http:// dx.doi.org/10.1001/archpedi.156.5.438

23. Lou C, Zhao Q, Gao E, Shah HI. 2006. Can the Internet Be Used Effectively to Provide Sex Education to Young People in China? J Adolesc Health. 39, 720-28. http:// dx.doi.org/10.1016/j.jadohealth.2006.04.003

24. MAYISHA II Collaborative Group. (2005). Assessing the Feasibility and Acceptability of Community-based Prevalence Surveys of HIV among Black African in England. London: Health Protection Agency Centre for Infections.

25. McDonald JH. (2008). The Handbook of Biological Statistics. [e-Book]. Baltimore, Maryland: Sparky House Publishing. Available from: http://udel.edu/ mcdonald/ statpermissions.html

26. Ministry of Health Uganda. (2005). HIV/AIDS Sero-Behavioral Survey, 2004-2005. Preliminary Report, Kampala.

27. Muller TR. (2005). HIV/AIDS, Gender and Rural Livehoods in Sub-Saharan Africa. Netherlands: Wageningen Academic Publishers. 
28. Noar SM, Pierce LB, Black HG. 2010. Can Computer-Mediated Interventions Change Theoretical Mediators of Safer Sex? A Meta-Analysis. Hum Commun Res. 36(3). http:// dx.doi.org/10.1111/j.1468-2958.2010.01376.x

29. Noar SM, Black HG, Pierce LB. 2009. Efficacy of computer technology-based HIV prevention interventions: a meta-analysis. AIDS. 23(1), 107-15. http://dx.doi.org/10.1097/ QAD.0b013e32831c5500

30. Pallant J. (2007). A Step-By-Step Guide to Data Analysis Using SPSS Version 15. 3rd ed. England: Open University Press.

31. Pearson J. 2006. Personal Control, Self-Efficacy in Sexual Negotiations, and Contraceptive Risk among Adolescents: The Role of Gender. Sex Roles. 54, 615-25. http:// dx.doi.org/10.1007/s11199-006-9028-9

32. Population Council. (2008). AIDSquest Survey Library. [online]. Available from: $\underline{\text { http:// }}$ www.popcouncil.org/horizons/ORToolkit/AIDSQuest/topics/knowledge.html. [accessed 20 January 2008].

33. Prochaska JO, DiClemente CC. 1982. Transtheoretical Therapy: Towards a more Integrative Model of Change. Psychotherapy. 19(3), 276-87. http://dx.doi.org/10.1037/ $\underline{\text { h0088437 }}$

34. Remenyi D, Williams B, Money A, Swartz E. (2002). Doing Research in Business and Management: An Introduction to Process and Methods. London: Sage.

35. Richie J, Stewart M, Ellerton ML, Thompson D, Meade D, et al. 2000. Parents'

Perceptions of the Impacts of a Telephone Support Group Intervention. J Fam Nurs. 6(1), 25-45. http://dx.doi.org/10.1177/107484070000600103

36. Rimal RN. 2000. Closing the Knowledge-Behavior Gap in Health Promotions: The Mediating Role of Self-efficacy. Health Commun. 12, 219-37. http://dx.doi.org/10.1207/ S15327027HC1203 01

37. Roberto AJ, Zimmerman RS, Carlyle KE, Abner EL. 2007. A computer-based Approach to Preventing Pregnancy, STD, and HIV in Rural Adolescents. J Health Commun. 12, 53-76. http://dx.doi.org/10.1080/10810730601096622

38. Shepherd J, Kavanagh J, Picot J, Cooper K, Harden A, et al. (2010). The Effectiveness and Cost-effectiveness of Behavioral Interventions for the Prevention of Sexually

Transmitted Infections in Young People aged 13-19: A Systematic Review and Economic Evaluation. Health Technology Assessment NIHR HTA Program. [online] Available from: http://www.hta.ac.uk [accessed on 07 July 2010].

39. Sionean C, DiClemente R, Wingood G, Crosby R, Cobb B, et al. 2002. Psychosocial and Behavioral Correlates of Refusing Unwanted Intercourse among African-American Female Adolescents. J Adolesc Health. 30, 55-63. http://dx.doi.org/10.1016/S1054-139X(01)00318-4 40. Stephenson JM, Strange V, Allen E, Copas A, Johnson A, et al. 2008. The Long-term Effects of a Peer-led Sex Education Programme (RIPPLE): A Cluster Randomised Trial in Schools in England. PLoS Med. 5(11), e224. doi:http://dx.doi.org/10.1371/ journal.pmed.0050224.

41. Stout PA, Villegas J, Kim H. 2001. Enhancing learning through the Use of Interactive tools on Health-related Websites. Health Educ Res. 16(6), 721-33. http://dx.doi.org/10.1093/ her/16.6.721

42. Thomson R, Holland J. (1998). Sexual Relationships, Negotiation, and Decision Making. In Coleman J and Roker D (eds), Teenage Sexuality: Health, Risks, and Education, 59-80. Amsterdam: Harwood. 
43. Tian L, Tanga S, Cao W, Zhang K, Li V, et al. 2007. Evaluation of a web-based intervention for improving HIV/AIDS knowledge in rural Yunnan, China. AIDS. 8, 137-42. http://dx.doi.org/10.1097/01.aids.0000304709.02412.3c

44. Walker D, Gutierrez JP, Torres P, Bertozzi SM. 2006. HIV Prevention in Mexican Schools: Prospective Randomised Evaluation of the Intervention. BMJ. doi:http:// dx.doi.org/10.1136/bmj.38796.457407.80.

45. Wantland DJ, Portillo CJ, Holzemer WL, Slaughter R, McGhee EM. 2004. The effectiveness of Web-based vs non-Web-based Interventions: A Meta Analysis of Behavioral Change Outcomes. J Med Internet Res. 6, e40. http://dx.doi.org/10.2196/jmir.6.4.e40 46. Wight D, Raab GM, Henderson M, Abraham C, Buston K, et al. 2002. Limits of Teacher Delivered Sex Education: Interim Behavioral Outcomes from Randomised Trial. BMJ. 324, 1430. http://dx.doi.org/10.1136/bmj.324.7351.1430

47. Wikgren M. 2003. Everyday health information exchange and citation behavior in Internet discussion groups. New Review of Information Behavior Research. 4, 225-39. http:// dx.doi.org/10.1080/14716310310001631543

48. Wyatt J, Wyatt S. 2003. When and How to Evaluate Health Information Systems? Int J Med Inform. 69, 251-59. http://dx.doi.org/10.1016/S1386-5056(02)00108-9

49. Wyatt J. 2000. Evaluating Electronic Consumer Health Materials. BMJ. 320, 159-60. 50. Biraro S, Shafer LA, Kleinschmid I, Wolff B, Karabalinde A, et al. 2009. Is Sexual Risk Taking Behavior Changing in Rural South-West Uganda? Behavior Trends in a Rural Population Cohort 1993-2006. Sex Transm Infect. 85, i3-11. http://dx.doi.org/10.1136/ sti.2008.033928

51. Young SD, Rice E. 2011. Online Social Networking Technologies, HIV Knowledge, and Sexual Risk and Testing Behaviors Among Homeless Youth. AIDS Behav. 15(2), 253-60. http://dx.doi.org/10.1007/s10461-010-9810-0 